\title{
O DIREITO FUNDAMENTAL AO BOM GOVERNO E 0 DEVER DE PROTEÇÃO ESTATAL: UMA ANÁLISE DAS COMPETÊNCIAS FEDERATIVAS À IMPLEMENTAÇÃO DE POLÍTICAS DE PREVENÇÃO E REPRESSÃO AOS ATOS DE MALVERSAÇÃO DO PATRIMÔNIO PÚBLICO
}

THE FUNDAMENTAL RIGHT TO GOOD GOVERNMENT AND THE STATE PROTECTION DUTY: AN ANALYSIS OF THE FEDERAL COMPETENCES FOR THE IMPLEMENTATION OF PREVENTION AND REPRESSION OF ACTS OF MISAPPROPRIATION OF PUBLIC ASSETS POLICIES

Felipe Dalenogare Alves

Mônia Clarissa Hennig Leal

\section{RESUMO}

0 presente trabalho expõe o resultado de uma pesquisa bibliográfica, concebida a partir do método dedutivo, para fins de abordagem, e monográfico, a título procedimental, acerca da necessidade de estabelecimento de políticas públicas e a consequente atribuição de competências para a prevenção e repressão de atos desonestos por parte dos agentes públicos, como medida indispensável ao dever de proteção do Estado na concretização do direito fundamental ao bom governo. Assim, a pesquisa justifica-se pela necessidade de esclarecimento de importantes pontos que cercam a problemática que motiva a pesquisa, como a seguinte questão: estabelecida a fundamentalidade ao direito ao bom governo e constatada a necessidade de políticas de prevenção e repressão aos atos desonestos no exercício do Poder emanado do povo, a quais Entes federativos compete o estabelecimento de normas objetivando a 
responsabilização administrativa, civil, penal e por atos de improbidade? Para tanto, o trabalho estrutura-se em duas partes. Na primeira, realiza-se um discurso de fundamentação acerca do direito fundamental ao bom governo, para, em um segundo momento, se realizar uma análise dos instrumentos internacionais que versam sobre as obrigações estatais de se estabelecerem políticas internas de prevenção e repressão aos atos corruptivos, estudando-se seus reflexos e quais dessas medidas foram implementadas no âmbito doméstico, a fim de, na última seção, fazer-se uma análise normativo-constitucional acerca das competências federativas à sua consecução, buscando-se a proteção do direito fundamental ao bom governo. Dentre os resultados encontrados, verificou-se que, quanto ao estabelecimento de normas objetivando a responsabilização civil e penal, a competência é privativa da União, enquanto as normas sobre direito administrativo são comuns a todos os Entes federativos, pairando controvérsia, entretanto, quanto à competência para legislar sobre improbidade administrativa, o que poderia ocorrer uma invasão de competências por parte da União, como se verá no decorrer do trabalho.

Palavras-chave: Competências federativas. Corrupção. Dever de proteção estatal. Direito fundamental ao bom governo. Improbidade administrativa.

\section{ABSTRACT}

This paper presents the results of a bibliographical research, conceived from the deductive method, for purposes of approach, and monographic, on a procedural basis, on the need to establish public policies, and the consequent attribution of competences, for the prevention and repression of dishonest acts by public agents, as an indispensable measure to the State's duty to protect the fundamental right to good government. Thus, the research is justified by the need to clarify important points that surround the problematic that motivates the study, such as the following question: established the fundamentality of the right to good government and established the need for policies of prevention and repression of dishonest acts in the exercise of the Power emanated from the people, to which federative entities is responsible for the establishment of norms aiming at administrative, civil, criminal and for acts of improbity? For this, the work is structured in two parts. In the first, there is a speech about the fundamental right to good government, in order to analyze the international instruments that deal with state obligations to establish internal policies for the prevention and repression of corrupt acts, studying its reflexes and which of these measures were implemented in the domestic scope, in order to, in the last section, make 
a normative-constitutional analysis about the federative competencies to its attainment, seeking the protection of the fundamental right to good government. Among the results found, it was verified that, regarding the establishment of norms aiming at civil and criminal accountability, the competence is private to the Union, whereas the rules on administrative law are common to all entities, while controversy remains, however, regarding competence to legislate on administrative improbity, as will be seen in the course of the paper.

Keywords: Federative competencies. Corruption. Duty of state protection fundamental right to good government. Administrative improbity.

\section{INTRODUÇÃo}

Este artigo apresenta o resultado de uma pesquisa acerca da necessidade de estabelecimento de políticas públicas e a consequente atribuição de competências, para a prevenção e repressão de atos desonestos por parte dos agentes públicos, como medida indispensável ao dever de proteção do Estado à concretização do direito fundamental ao bom governo.

A fundamentalidade do direito ao bom governo, decorrente do próprio regime democrático-representativo, é tema atual e não deixa de passar pela necessidade de pré-compreensão da noção luhmanniana de "Constituição como aquisição evolutiva", no sentido de que esta deve acompanhar as transformações sociais.

Com isso, o discurso de fundamentação acerca do direito fundamental ao bom governo exige uma interpretação constitucional aberta, a ser realizada considerando os interesses sociais, políticos e econômicos preponderantes, mas, que, essencialmente, congregue o estado espiritual de seu tempo, possibilitando-se a evolução do texto constitucional, constantemente adaptado à realidade de determinada comunidade, o que também deve ocorrer com o art. 14, caput, da Constituição Federal de 1988, que versa sobre o exercício da soberania popular através da democracia representativa e participativa.

Atribuída a fundamentalidade ao direito ao bom governo, sua concretização acarreta o estabelecimento de políticas públicas. Dentre elas, também decorrente do dever de proteção estatal, imposto pela dimensão objetiva deste direito, está a imposição de se estabelecer um 
arcabouço normativo que previna e reprima os atos de desonestidade, por parte dos agentes públicos em geral, o qual é induzido principalmente pelos instrumentos internacionais de que o Estado Brasileiro é parte, tais como a Convenção das Nações Unidas contra a Corrupção e a Convenção Interamericana contra a Corrupção.

Constatada a necessidade de estabelecimento dessas medidas, resta analisar a distribuição de competências dentro do sistema federativo adotado pelo Brasil. Estas irão variar entre atribuições legislativas, a depender da matéria em análise, e executivas, no caso específico deste trabalho, comum a todos os Entes, uma vez tratar-se de conservação do patrimônio público.

Neste contexto, a pesquisa justifica-se pela necessidade de esclarecimento de importantes pontos que cercam a problemática que motiva a pesquisa, o qual encontra seu cerne na seguinte questão: estabelecida a fundamentalidade do direito ao bom governo e constatada a necessidade de políticas de prevenção e repressão aos atos desonestos no exercício do Poder emanado do povo, a quais Entes compete o estabelecimento de normas objetivando a responsabilização administrativa, civil, penal e por atos de improbidade?

Objetivando-se encontrar resultados ao problema apresentado, realiza-se uma pesquisa bibliográfica, utilizando-se do método dedutivo, para a realização da abordagem, servindo-se, ainda, do método monográfico para fins procedimentais. Dessa forma, o trabalho estrutura-se em três partes.

Na primeira, realiza-se um discurso de fundamentação acerca do direito fundamental ao bom governo, estabelecendo sua base constitucional e sua interligação à própria noção de Estado Democrático de Direito. Em um segundo momento, analisam-se os instrumentos internacionais que versam sobre as obrigações estatais de se estabelecerem políticas internas de prevenção e repressão aos atos corruptivos, estudando-se seus reflexos e quais dessas medidas foram implementadas no âmbito doméstico, para, na última seção, fazer-se uma análise normativo-constitucional acerca das competências federativas à sua consecução, buscando-se a proteção do direito fundamental ao bom governo. 


\section{O DIREITO FUNDAMENTAL AO BOM GOVERNO: A PREVENÇÃO E A REPRESSÃO AOS ATOS DE DESONESTIDADE COMO PARTE INTEGRANTE DE SEU CONTEÚDO}

A fundamentalidade do direito ao bom governo acarreta, diretamente, a necessidade de implementação de políticas públicas à sua concretização, políticas essas que competem, em um primeiro momento, ao Estado como um todo, mas que, por competências federativas próprias, previamente estabelecidas na própria Constituição, delineiam horizontes distintos, a depender da perspectiva a ser dada à política.

0 estabelecimento da fundamentalidade do direito ao bom governo passa por uma pré-compreensão da noção de Constituição como aquisição evolutiva, traçada por Luhmann (1996), ou seja, de que há transformações sociais que produzem uma nova necessidade de sentido à Constituição.

Significa dizer que, atualmente, a construção (planejada) da Constituição não deve ser vista como um processo único, ocorrido de uma só vez por ocasião da Constituinte, mas como uma constante reconstrução (replanejamento), através da interpretação constitucional (LUHMANN, 1996, p. 1).

Esta interpretação não se encontra, por sua vez, adstrita à jurisdição, em especial aos órgãos judicantes, devendo ser compartilhada, como um fenômeno pluralista, de que todos participem. Para tanto, ela pode e deve ser realizada pela sociedade ${ }^{1}$, sob uma perspectiva "aberta" (HÄBERLE, 2003, p. 150). Por conseguinte, o conteúdo de determinação das normas constitucionais passa a ser mínimo, estimulando a sua abertura e tornandoas eminentemente "principiológicas", reforçando-se, por sua vez, o próprio papel da interpretação.

Ao se levar em conta os ensinamentos de Hesse (1991, p. 20) de que constitui imperativo à força normativa da Constituição que ela considere não apenas os interesses sociais, políticos e econômicos preponderantes, mas, essencialmente, congregue o estado espiritual de seu tempo, será por intermédio da abertura das normas constitucionais que isso se tornará possível, uma vez que, assim ocorrendo, se possibilitará a 
evolução do texto constitucional, constantemente adaptado à realidade de determinada comunidade.

É esta abertura dos dispositivos constitucionais que possibilitará a conjugação entre a Constituição "real" e a "jurídica". Isso porque, como aponta Hesse (1991, p. 15-16), embora se condicionem mutuamente, uma não depende da outra, assim a "Constituição Real” dependerá da eficácia produzida pela "Constituição Jurídica”, sendo a sua interpretação o elo que fará a intermediação.

Nesse sentido, há de se afirmar que o processo de concretização da Constituição aberta é um processo metódico, que parte do texto da norma (CANOTILHO, 2000, p. 1185), dando-se na medida em que se institui a necessidade, por parte do intérprete, de compreensão da norma além do seu teor literal, composta por dois aspectos em igual nível hierárquico: seu programa e seu domínio. Enquanto o primeiro se refere ao aspecto textual, ou seja, seu conteúdo semântico (a "ordem jurídica", tradicionalmente compreendida), o segundo condiz com a sua realidade social (âmbito de regulamentação), é o seu caráter empírico (MÜLLER, 2000, p. 59).

Em vista disso, Müller (2000, p. 58-59) destaca que "Direito" e "realidade" não são grandezas que subsistem de forma independente. A concretização da norma só se dá com o equilíbrio entre os elementos "normativos" e os elementos "empíricos". Isso posto, a norma jurídica demonstra ser um modelo de ordem materialmente concretizado, pois há, de um lado, o esboço vinculante do ordenamento em linguagem e, de outro, a harmonia e a unidade dos fatores ordenantes e ordenados, que constituem a práxis do Direito.

A concretização da norma constitucional é tão importante (a fim de que não se torne mera promessa vazia, desprovida de conteúdo), que o autor propõe a substituição do termo "interpretação do texto da norma" pelo termo "concretização da norma". Para Müller (2000, p. 61), "enquanto forem indicados como 'métodos' da práxis e da ciência jurídica somente regras de interpretação, a estrutura da realização prática do Direito terá sido compreendida de forma equivocada". Assim, "a interpretação do teor literal da norma é um dos elementos mais importantes no processo de concretização, mas somente um elemento" dela. 
Em decorrência desse processo interpretativo, sob a égide do princípio republicano da soberania popular e da representação, insculpidos no art. 1oㅗ § único, da Constituição da República de 1988, a leitura do seu art. 14 não pode cingir-se ao texto da norma ${ }^{2}$. É deste dispositivo que se tenta demonstrar que se extrai o direito fundamental ao bom governo, afinal, se a soberania popular é exercida por seus representantes, surge um dever de bem representar, advindo da dimensão objetiva deste direito, como se verá a seguir ${ }^{3}$.

A fundamentalidade do direito ao bom governo ficará ainda mais evidente, caso seja aprovada a reforma administrativa proposta por intermédio da PEC no 32/2020, que insere no caput do art. 37 da Constituição Federal, como princípio à Administração Pública a "boa governança pública”.

Deve consignar-se que os direitos fundamentais não se limitam ao status de direitos subjetivos, constituindo-se também em elementos valorativos (decisões de mais alta carga de valor, tomadas pelo constituinte), com caráter objetivo, irradiando sua eficácia sobre todo o ordenamento jurídico e servindo de diretrizes a serem observadas por todos os Poderes do Estado (SARLET, 2007, p. 168).

No dizer de Pérez Luño (2013, p. 17), por uma perspectiva objetiva axiológica, "os direitos fundamentais representam o resultado do acordo básico das diferentes forças sociais, alcançado a partir de relações de tensão e dos consequentes esforços de cooperação destinados a realização de metas comuns".

Assim, "corresponde aos direitos fundamentais um importante papel legitimador das formas constitucionais do Estado de Direito, já que constituem os pressupostos de consenso sobre os quais qualquer sociedade democrática deve ser construída" (PÉREZ LUÑO, 2013, p. 17).

Ainda por intermédio de sua dimensão objetiva, os direitos fundamentais possuem a função "de sistematizar o conteúdo axiológico objetivo do ordenamento democrático, que a maioria dos cidadãos conferem consentimento e condicionam seu dever de obediência ao Direito", além de comportarem "a garantia essencial de um processo político livre e aberto, como elemento informador do funcionamento de qualquer sociedade pluralista" (PÉREZ LUÑO, 2013, p. 17). 
Defender que do art. 14 da Constituição Federal de 1988 decorre o direito ao bom governo significa atribuir ao direito fundamental à democracia representativa constante em seu texto, além de uma dimensão subjetiva, que autoriza o titular (povo) a reclamar ações (omissivas ou comissivas) para sua concretização, uma dimensão objetiva, que impõe um compromisso e respeito dos Poderes constituídos a este mesmo direito.

Em decorrência, no exercício do mandato de representação do Poder, por força dessa dimensão objetiva, os agentes públicos assumem o dever de "agir sempre de modo a conferir a maior eficácia possível aos direitos fundamentais (prestar os serviços públicos necessários, exercer o poder de polícia e legislar para o fim de dar concretude aos comandos normativos constitucionais)" (CLÈVE, 2006, p. 4).

Também da dimensão objetiva decorre que os direitos fundamentais, como vetores de atuação do poder público, passam a pautar as ações deste, objetivando-se sua otimização. Para tanto, um agir em conformidade com o dever de honestidade, centrado no cidadão, torna-se indissociável do direito ao bom governo.

O discurso de fundamentação sobre a fundamentalidade deste direito passa pelo fato de que "na democracia, as instituições políticas não são de propriedade de políticos ou altos agentes públicos, mas são de domínio popular, são dos cidadãos, das pessoas de carne e osso" (RODRIGUEZ-ARANA, 2012, p. 30).

Desse modo, há de se dizer que, se as instituições públicas são da soberania popular, de onde emana o Poder do Estado (art 1ํㅡ, § 1ํㅡㄹ da Constituição da República de 1988), torna-se cristalino que devem estar voltadas ao interesse geral e objetivo, para atender as necessidades coletivas (RODRIGUEZ-ARANA, 2012, p. 30).

Tem-se, portanto, que o conceito de bom governo é amplo, mas comporta uma dimensão jurídica, que se encontra vinculada a princípios, padrões, procedimentos e práticas que buscam garantir o adequado exercício do poder e da tomada de decisão por parte dos governantes, constituindo-se como um princípio fundamental republicano, calcado nos valores que inspiram o próprio Estado Democrático de Direito, constituindo-se, assim, à luz do direito público contemporâneo, em um mecanismo de direção e de atuação estatal (CASTRO, 2014, p. 19). 
Seguindo nessa linha, o Conselho de Direitos Humanos das Nações Unidas delineou, na Resolução no 2000/64, aprovada em 26 de abril de 2000, cinco atributos indispensáveis ao direito ao bom governo, sendo eles: 1) transparência; 2) responsabilidade; 3) accountability; 4) participação; 5) respostas às demandas sociais ${ }^{4}$. A resolução ainda salienta a necessidade de um esforço internacional conjunto para a consolidação do direito ao bom governo, independentemente do estágio econômico do país.

É dentro da concepção de accountability que se encontram as políticas públicas que objetivam o controle e a responsabilização de governantes frente aos governados, principalmente no sentido de coibir a malversação dos escassos recursos públicos, os quais devem ser geridos dentro de um primado de honestidade e de preocupação com o bem comum.

Assim, na próxima seção do trabalho, será realizada a análise dos principais instrumentos internacionais que objetivam prevenir e reprimir a malversação dos recursos públicos, incompatível com o direito ao bom governo, analisando-se, também, algumas políticas públicas internas que possam ter sido induzidas por esses instrumentos internacionais aderidos pelo Estado Brasileiro.

\section{A NORMATIZAÇÃO CONVENCIONAL SOBRE OS ATOS DE DESONESTIDADE E O SEUS REFLEXOS NO ESTABELECIMENTO DE POLÍTICAS PÚBLICAS NO ÂMBITO INTERNO}

Nesta seção, será abordado um dos elementos que integram o terceiro componente do direito ao bom governo citado no item anterior (accountability), centrado na necessidade de políticas do Estado para a prevenção e repressão aos atos maléficos à gestão da coisa pública, a exemplo dos atos corruptivos, contrários à probidade administrativa, sob uma perspectiva de cooperação e de indução internacional, para ações concretas por parte do Estado Brasileiro.

Levando-se em consideração que as práticas corruptivas e ímprobas não se cingem a um único ambiente sócio-político, mas possuem um status global, torna-se difícil a atuação isolada de um único Estado 
objetivando-se seu controle, razão pela qual tanto a normatização quanto a cooperação internacional tornaram-se ferramentas importantes nesta tarefa, principalmente no que tange à responsabilização dos agentes ativos de tais condutas (RAMINA, 2008, p. 43), que, como visto, é considerado pela ONU como elemento do bom governo.

Para a consecução dessa proposta, de internacionalização da prevenção e de repressão às práticas ímprobas, a Organização das Nações Unidas (ONU), em um âmbito global ${ }^{5}$, e a Organização dos Estados Americanos (OEA), com uma atuação regional, juntamente com Organizações Não-Governamentais situadas em distintos países, vêm participando, em conjunto com os Estados, na elaboração de instrumentos normativos e práticas que diminuam os níveis de corrupção governamental (RAMINA, 2008, p. 43-44).

Dentre os instrumentos internacionais editados pela Organização nas Nações Unidas, destacam-se a Resolução no 51/59, da Assembleia Geral, de 12 de dezembro de 1996, que aprova o Código Internacional de Conduta para os titulares de cargos públicos ${ }^{6}$; a Resolução no 51/191, da Assembleia Geral, de 16 de dezembro de 1996, que aprova a Declaração das Nações Unidas contra a Corrupção e o Suborno nas transações comerciais internacionais ${ }^{7}$; a Resolução no 54/128, da Assembleia Geral, de 17 de dezembro de 1999, com conclusões e recomendações aprovadas pela Reunião do Grupo de Expertos sobre a Corrupção e seus Circuitos Financeiros, celebrada em Paris, nos dias 30/03 a 01/04/19998; as Resoluções no 67/192, de 20 de dezembro de 2012, no 68/195, de 18 de dezembro de 2013, e no 69/199, de 18 de dezembro de 2014, ambas da Assembleia Geral, que versam sobre ação preventiva e luta contra as práticas corruptivas e a transferência do produto da corrupção e medidas para facilitar a recuperação de ativos e a restituição destes a seus legítimos proprietários $^{9}$, em particular os países de origem e a Convenção das Nações Unidas contra a Corrupção, adotada em 31 de outubro de $2003^{10}$.

No âmbito regional, merece destaque a Convenção Interamericana contra a Corrupção, aprovada pela Organização dos Estados Americanos em 29 de março de 1996, antes mesmo da Convenção da ONU ${ }^{11}$. Doravante, realizar-se-á uma breve análise dos dispositivos internacionais mencionados, para, posteriormente, se verificar algumas políticas e ações 
de prevenção e repressão às práticas desonestas no Brasil, essenciais à concretização do direito fundamental ao bom governo, que possam ter sido originadas destes instrumentos internacionais.

No que refere à Resolução no 51/59, da Assembleia Geral, de 12 de dezembro de 1996, que aprova o Código Internacional de Conduta para os titulares de cargos públicos, importa salientar que, preliminarmente, o instrumento apresenta princípios gerais, como 1) a obrigação de atuação em prol do interesse público; 2) a obrigação de uma atuação eficiente e eficaz, pautada na legalidade; e 3) a obrigação de uma atuação imparcial e impessoal, sem preferências ou discriminações.

A segunda parte do código trata dos conflitos de interesses e dos impedimentos, trazendo os seguintes preceitos: 1) a não utilização de seu cargo para favorecer interesses pessoais ou econômicos próprio ou de familiares; 2) a obrigatoriedade de declarar seus interesses econômicos, empresariais ou financeiros que possam ocasionar possíveis conflitos de interesses; 3) a não utilização indevida, em atividades não relacionadas à função pública, de dinheiro, bens, serviços ou informação adquirida no cumprimento ou como resultado do cargo público; e 4) o acatamento das normas relativas aos impedimentos posteriores, a fim de evitar aproveitamento indevido de eventuais vantagens advindas com o antigo cargo.

A terceira parte refere-se à declaração de bens, preceituando-se que os titulares de cargos públicos deverão declarar ou revelar seus ativos e passivos pessoais, bem como de seus cônjuges e outros dependentes.

A quarta parte trata da não aceitação de agrados ou outros favores, estabelecendo-se que os agentes públicos não solicitarão nem receberão, direta ou indiretamente, nenhum agrado ou outros favores que possa influenciar no desempenho de suas funções e no comprimento de seus deveres.

A quinta seção aborda o trato das informações confidenciais, prevendo-se a guarda e o sigilo das informações das quais se tome conhecimento em virtude da função, excetuando-se os casos previstos em lei ou exigidos pela justiça, o que deverá ser mantido inclusive após o exercício do cargo função pública. 
A última seção trata do desempenho de atividades políticas pelos ocupantes de cargos públicos, fora do âmbito de suas atribuições, no sentido de manutenção do desempenho imparcial de suas funções e obrigações.

Prosseguindo-se com a análise dos dispositivos, outro instrumento importante é a Declaração das Nações Unidas contra a Corrupção e o Suborno nas transações comerciais internacionais, aprovada pela Resolução no 51/191, da Assembleia Geral, de 16 de dezembro de $1996^{12}$.

0 documento, ainda que de caráter declaratório, traz basicamente 12 (doze) compromissos aos Estados-membros, para que estes, de modo individual ou induzido por organizações internacionais e regionais, os adotem, em conformidade com a Constituição e os princípios fundamentais de cada Estado.

$01^{\text {o }}$ condiz com o compromisso de se adorar medidas efetivas e concretas para lutar contra todas as formas de corrupção, suborno e demais práticas ilícitas no âmbito das negociações comerciais internacionais, dentre elas o efetivo cumprimento das leis que as proíbem, ou, nos Estados que ainda não as tiverem editado, a sua adoção, além do incentivo às empresas públicas e privadas que realizem suas transações de acordo com a presente declaração.

$02^{\circ}$ e o $3^{\circ}$ objetivam, com a adoção de medidas coordenadas, tipificar como delito os atos de suborno de agentes públicos estrangeiros, incluindose, entre outros, o oferecimento, a promessa, a entrega a solicitação, a exigência, o aceite ou o recebimento, de qualquer pagamento, presente ou vantagem de qualquer espécie, direta ou indiretamente, por particular ou empresa pública ou privada, incluindo-se as transnacionais, a qualquer agente público ou político, por ter cumprido ou deixado de cumprir suas obrigações como agente público ou político ou representante em um negócio comercial internacional. 0 7ํㅡ busca, também, a tipificação do delito de enriquecimento ilícito destes agentes.

$04^{\circ}$ refere-se à proibição de que os valores pagos como suborno sejam considerados para fins tributários, analisando-se os possíveis meios para alcançá-lo. 0 50 e o 6a aludem, respectivamente, a elaboração ou manutenção de normas e práticas que aumentem a transparência nas negociações internacionais, alertando-se aos particulares e às empresas que efetuam tais transações a evitar a corrupção, o suborno e 
as demais práticas ilícitas conexas, lutando contra elas e a elaboração ou o fomento de códigos comerciais, normas e práticas que proíbam estes atos corruptivos em tais negócios.

O 8o aborda a prestação mútua de assistência e cooperação nas investigações penais e demais procedimentos judiciais relacionados a essas práticas corruptivas, por intermédio de leis internas, tratados bilaterais ou outros atos internacionais, incluindo-se a apresentação de dados e documentos, tomada de declarações ou de documentos necessários às investigações; a notificação do início e dos resultados de procedimentos judiciais aos demais Estados que possam ter competência para reprimir tais delitos; e os procedimentos para extradição. 0 9o enfatiza que estas medidas devem incluir, também, o acesso a documentos e registros sobre as transações comerciais internacionais e à identidade das pessoas que cometam atos de suborno.

O $10^{\circ}$ vela para que as disposições internas relativas ao sigilo bancário não travem nem obstaculizem as investigações e demais procedimentos judiciais relativos às práticas corruptivas, prezando-se pela cooperação plena entre os Estados que tentam obter as informações. $011^{\circ}$ ressalta, porém, que as medidas necessárias para o cumprimento da declaração devem respeitar plenamente a soberania e a jurisdição territorial dos Estados-membros, bem como os direitos e obrigações constantes nos tratados internacionais, sem violar os direitos humanos e as liberdades fundamentais.

Por fim, o $12^{\circ}$ compromisso condiz com a necessidade de que o estabelecimento de competências relativas à repressão às práticas corruptivas obedeça aos princípios de direito internacional, no tocante à aplicação extraterritorial das leis de um Estado.

Outro instrumento de significativa importância à prevenção e repressão às patologias corruptivas, que será analisado a seguir, é a Convenção das Nações Unidas contra a Corrupção, adotada em 31 de outubro de 2003, promulgada no Brasil em 31 de janeiro de 2006, por intermédio do Decreto no 5.687, a qual contém 71 artigos.

Em sede preambular, os Estados partes destacam, dentre outras preocupações, a gravidade dos problemas e as ameaças à estabilidade e segurança das sociedades democráticas advindas com a corrupção, 
principalmente por se tratar de um fenômeno transnacional, que penetra em diversos setores sociais, e que, muitas vezes, envolve o crime organizado, ocasionando enriquecimento pessoal ilícito, nocivo à democracia, às economias nacionais e ao próprio Estado de Direito, necessitando, assim, de um enfoque amplo e multidisciplinar, com disponibilidade de assistência técnica e instituições especializadas, que trabalhem em cooperação internacional, mas com observância ao devido processo legal.

Destaca-se que a finalidade da Convenção é promover, fortalecer, facilitar e apoiar medidas eficazes e eficientes de prevenção e repressão à corrupção, além da cooperação internacional e assistência técnica, incluindo-se a recuperação de ativos, estabelecendo-se uma concepção de integridade na gestão dos assuntos e dos bens públicos.

Sua aplicação dar-se-á no âmbito da prevenção e repressão (com a devida investigação e instrução criminal), em observância ao princípio da igualdade soberana e integridade territorial, não sendo necessário, salvo disposição legal em contrário, dano ou prejuízo patrimonial ao Estado-parte.

Dentre as medidas preventivas estabelecidas na Convenção, especialmente as previstas nos artigos 5ํ e 6ํㅡ, destacam-se a necessidade de implementação de políticas e práticas de prevenção à corrupção, promovendo-se a sua avaliação periódica, para verificar a eficiência e eficácia; o estabelecimento de órgãos independentes, responsáveis pela supervisão, coordenação e aplicação deste trabalho preventivo, utilizandose, principalmente, da difusão dos conhecimentos em matéria de prevenção da corrupção; a dispensa de atenção especial ao setor público, com a adoção de sistemas de convocação, contratação, retenção, promoção e aposentadoria de funcionários públicos, objetivando-se a redução da vulnerabilidade aos atos corruptivos, sem deixar de estabelecer códigos de conduta visando a sua integridade, honestidade e responsabilidade.

Além disso, como prática preventiva, os Estados-partes deverão adotar medidas transparentes, objetivas e apropriadas de licitação e contratação pública, bem como disponibilizar as informações públicas ao cidadão (art. 9º). A Convenção não desconsidera, no art. 11, a necessidade do estabelecimento de medidas preventivas à corrupção no âmbito do Poder Judiciário e do Ministério Público, ressaltando a necessidade de integridade destas instituições, dado o seu papel no combate ao fenômeno. 
No âmbito do setor privado, previstas no art. 12, as ações preventivas devem incluir a melhoria das normas contábeis e de auditoria, além dos códigos de conduta aplicados ao setor privado, e a necessária transparência, principalmente no que toca à divulgação do estado financeiro das empresas.

A norma convencional destaca, ainda, a importância do papel da sociedade na prevenção das práticas desonestas, estabelecendo a necessidade de fomento da participação ativa de pessoas e entidades não governamentais no controle social do poder público, para o qual deverá aumentar a transparência, com acesso eficaz à informação, e os canais de contribuição da cidadania aos processos de adoção de decisões (art. 13).

No que tange à repressão, com a penalização e a aplicação da lei, a Convenção estabelece, a partir do art. 15, que cada Estado-parte tomará as medidas legislativas e as demais necessárias para que seja tipificado como delito a prática de suborno de funcionários públicos nacionais, estrangeiros, de organizações internacionais públicas e de pessoas do setor privado; a malversação ou o peculato no setor público e privado, a apropriação indébita ou outras formas de desvio de bens por um funcionário público, o tráfico de influências, a usurpação da função pública, o enriquecimento ilícito, a lavagem de produto do crime, o encobrimento de bens, e a obstrução da justiça.

Ao tratar da responsabilidade pelos delitos previstos na Convenção, seja na preparação, tentativa ou consumação, se estabelece a necessidade de responsabilização das pessoas jurídicas independentemente das pessoas físicas (na esfera penal, civil e administrativa), bem como qualquer forma de participação, seja ela como cúmplice, colaborador ou instigador.

Dentre outros dispositivos, a Convenção, no art. 29, ainda traz a necessidade de ampliação do prazo de prescrição para o início dos processos em virtude da prática dos delitos de corrupção, além da dilação de prazo ou interrupção da prescrição quando o réu se evadir da administração da justiça e a imposição de sanções mínimas, como a inabilitação, por decisão judicial ou outro meio adequado, para o exercício de cargo público ou em empresas estatais, conforme o art. 30.

Há de se destacar, ainda, a previsão, no art. 31, de ferramentas cautelares ao auxílio do combate às práticas corruptivas, como o embargo preventivo, a apreensão e confisco; a proteção aos denunciantes, 
testemunhas, peritos e vítimas; a indenização por danos e prejuízos; a instituição de órgãos e autoridades especializados; a cooperação com as autoridades encarregadas de fazer cumprir a lei e entre os organismos nacionais (interinstitucional) e o setor privado; a cooperação internacional, envolvendo a extradição, o translado de pessoas condenadas a cumprir pena, a assistência judicial recíproca, o enfraquecimento de ações penais, a cooperação em matéria de cumprimento da lei, o desenvolvimento de investigações conjuntas, a utilização de técnicas especiais de investigação.

Destacam-se os dispositivos do art. 51 e seguintes destinados à recuperação de ativos, como a prevenção e detecção de transferências de produto de delito, medidas para a recuperação direta de bens, mecanismos de recuperação de bens mediante a cooperação internacional para fins de confisco, a restituição e disposição de ativos, a instituição de departamentos de inteligência financeira e a celebração de acordos e tratados bilaterais e multilaterais objetivando esta recuperação.

No que tange à assistência técnica e intercâmbio de informações, há a previsão convencional de promoção da capacitação e assistência técnica, a recompilação, intercâmbio e análise de informações sobre a corrupção e a aplicação da convenção mediante o desenvolvimento econômico e assistência técnica, previstos no art. 60 .

Finalmente, no art. 65, assenta-se a necessidade de que cada Estadoparte adote, em conformidade com os princípios fundamentais de sua legislação interna, as medidas que sejam necessárias, incluídas medidas legislativas e administrativas, para garantir o cumprimento de suas obrigações de acordo com a presente Convenção, o que vai corroborar à dimensão objetiva do direito fundamental ao bom governo e o dever de proteção estatal $^{13}$ a este direito.

No âmbito regional, há a Convenção Interamericana contra a Corrupção, aprovada pela OEA em 29 de março de 1996, sendo ratificada e promulgada no Brasil, por meio do Decreto no 4.410, em 7 de outubro de 2002. No dizer de Ramina (2003, p. 201), “a Convenção Interamericana contra a Corrupção representa o primeiro instrumento internacional a tratar do tema da corrupção transnacional e constitui o exemplo pioneiro de ação jurídica regional no mundo em desenvolvimento". 
Preambularmente, os Estados-partes da OEA reconhecem que "a corrupção solapa a legitimidade das instituições públicas e atenta contra a sociedade, a ordem moral e a justiça, bem como contra o desenvolvimento integral dos povos" e que o seu combate "reforça as instituições democráticas e evita distorções na economia, vícios na gestão pública e deterioração da moral social", só sendo possível efetivá-lo com o fim da impunidade e com a erradicação da sociedade e com a cooperação entre os Estados.

Os propósitos da Convenção Interamericana muito se assemelham aos da Convenção da ONU, a qual foi inspirada na primeira. Dentre eles, estão a promoção e o fortalecimento do desenvolvimento dos instrumentos necessários para prevenir, detectar, punir e erradicar a corrupção, além do estabelecimento da cooperação entre os Estados-partes, objetivandose a eficácia das medidas e ações para tanto necessárias.

Dentre as medidas de prevenção à corrupção previstas no art. 3ํ, está o estabelecimento de normas de conduta aos funcionários públicos (e os respectivos mecanismos para a sua efetividade), contendo, dentre outros dispositivos, a prevenção de conflitos de interesses, a guarda e o uso adequado dos recursos públicos a si confiados, o estabelecimento sistemas para exigir que estes agentes levem ao conhecimento das autoridades competentes as práticas corruptivas de que tenham conhecimento.

Ademais, o artigo contempla dispositivos como a necessidade de qualificação e formação dos agentes públicos, sistema para declaração de bens e rendas, sistema de seleção dos agentes públicos e aquisição de bens e serviços assegurando-se transparência, equidade e eficiência, sistema de arrecadação e controle da renda estatal, leis que vedem o favorecimento tributário, sistemas que protejam as pessoas que denunciarem atos de corrupção, estabelecimento de órgãos de controle superior, ações que impeçam o suborno de agentes públicos nacionais e estrangeiros, mecanismos que propiciem a participação social no combate à corrupção e o estudo de medidas que levem em consideração a relação entre a remuneração equitativa e a probidade no serviço público.

No tocante ao âmbito de aplicação e à jurisdição, a Convenção prevê sua efetividade quando o presumido ato corruptivo seja cometido ou produza efeitos em um dos Estados-partes, sendo que estes devem adotar 
as medidas necessárias para o estabelecimento de sua jurisdição quando os delitos forem cometidos nos seus respectivos territórios, por um de seus cidadãos ou residente habitual ou quando o suspeito se encontrar em seu território e não puder ser extraditado (art. 5ํㅜ).

A convenção regional, reforçando a noção de dever de proteção estatal, associada a uma dimensão objetiva do direito fundamental ao bom governo prevê que os Estados-partes deverão adotar as medidas legislativas e as demais necessárias, visando tipificar como delito, além do suborno transnacional e do enriquecimento ilícito, os seguintes atos de corrupção previstos no Artigo 6º̄, parágrafo I:

a. a solicitação ou a aceitação, direta ou indiretamente, por um funcionário público ou pessoa que exerça funções públicas, de qualquer objeto de valor pecuniário ou de outros benefícios como dádivas, favores, promessas ou vantagens para si mesmo ou para outra pessoa ou entidade em troca da realização ou omissão de qualquer ato no exercício de suas funções públicas;

b. a oferta ou outorga, direta ou indiretamente, a um funcionário público ou pessoa que exerça funções públicas, de qualquer objeto de valor pecuniário ou de outros benefícios como dádivas, favores, promessas ou vantagens a esse funcionário público ou outra pessoa ou entidade em troca da realização ou omissão de qualquer ato no exercício de suas funções públicas;

c. a realização, por parte de um funcionário público ou pessoa que exerça funções públicas, de qualquer ato ou omissão no exercício de suas funções, a fim de obter ilicitamente benefícios para si mesmo ou para um terceiro;

d. o aproveitamento doloso ou a ocultação de bens provenientes de qualquer dos atos a que se refere este artigo; $\mathrm{e}$

e. a participação, como autor, coautor, instigador, cúmplice, acobertador ou mediante qualquer outro modo na perpetração, na tentativa de perpetração ou na associação ou confabulação para perpetrar qualquer dos atos a que se refere este artigo.

Por certo que a norma convencional, no art. 11, reconhece a necessária progressividade, tanto à harmonização do ordenamento interno, bem como à consecução dos objetivos propostos, impondo, ainda, o compromisso de que os Estados-partes tipifiquem como delito as seguintes condutas:

a. o aproveitamento indevido, em benefício próprio ou de terceiros, por parte do funcionário público ou pessoa no exercício de funções 
públicas de qualquer tipo de informação reservada ou privilegiada da qual tenha tomado conhecimento em razão ou por ocasião do desempenho da função pública;

b. o uso ou aproveitamento indevido, em benefício próprio ou de terceiros por parte de funcionário público ou pessoa que exerça funções públicas de qualquer tipo de bens do Estado ou de empresas ou instituições em que este tenha parte aos quais tenha tido acesso em razão ou por ocasião do desempenho da função;

c. toda ação ou omissão realizada por qualquer pessoa que, por si mesma ou por interposta pessoa, ou atuando como intermediária, procure a adoção, por parte da autoridade pública, de uma decisão em virtude da qual obtenha ilicitamente, para si ou para outrem, qualquer benefício ou proveito, haja ou não prejuízo para o patrimônio do Estado; e

d. o desvio de bens móveis ou imóveis, dinheiro ou valores pertencentes ao Estado para fins não relacionados com aqueles aos quais se destinavam a um organismo descentralizado ou a um particular, praticado, em benefício próprio ou de terceiros, por funcionários públicos que os tiverem recebido em razão de seu cargo, para administração, guarda ou por outro motivo.

Dentre os instrumentos de cooperação previstos na convenção, especialmente no art. 13 e seguintes, está o comprometimento à extradição para a responsabilização pelos delitos previstos na Convenção, a assistência técnica recíproca, a mais ampla assistência possível para identificar, localizar, bloquear, apreender e confiscar bens obtidos ou provenientes da prática dos delitos tipificados de acordo com esta Convenção, ou os bens usados para essa prática, ou o respectivo produto, o desembaraço do sigilo bancário, respeitando-se as garantias fundamentais.

Por fim, destaca-se a previsão convencional de que "o fato de os bens provenientes do ato de corrupção terem sido destinados a finalidades políticas ou a alegação de que um ato de corrupção foi cometido por motivações ou finalidades políticas não serão suficientes, por si sós, para considerá-lo como delito político ou como delito comum vinculado a um delito político" (art. 17).

No âmbito interno, houve a instituição de algumas políticas objetivando prevenir e reprimir a má gestão pública, sendo que, dentre os principais instrumentos normativos presentes no ordenamento jurídico interno, podemos destacar o Código de Ética Profissional do Servidor 
Público Civil do Poder Executivo Federal e o Código de Conduta da Alta Administração Federal, a Lei de Declaração de Bens e Rendas, a Lei de Improbidade Administrativa, a Lei de Acesso a Informação, a Lei Anticorrupção, e o projeto do Novo Código Penal Brasileiro.

No que se refere à compatibilização do ordenamento interno à Resolução no 51/59, da Assembleia Geral, de 12 de dezembro de 1996, que aprova o Código Internacional de Conduta para os titulares de cargos públicos, verifica-se que o Brasil conta com um Código de Ética Profissional do Servidor Público Civil do Poder Executivo Federal, aprovado em 22 de junho de 1994, ou seja, antes mesmo da Resolução 51/59, e o Código de Conduta da Alta Administração Federal, aprovado em 21 de agosto de 2000 , este sim, possivelmente influenciado pelo dispositivo internacional, ainda que nada conste na exposição de motivos.

Leal (2013, p. 65) sintetiza os principais pontos de regulação de ambos os códigos de ética, destacando os seguintes pontos tratados:

a) uso indevido do cargo público; b) enriquecimento ilícito no exercício da função; patrocínio de interesse privado perante a administração pública (tráfico de influência); c) violação de sigilo; d) uso de informação privilegiada; e) prestação de assessoria a entidade privada; f) atividade profissional paralela à função pública; g) hipóteses de conflito de interesse; h) limitações para atividade profissionais posteriores ao exercício do cargo (quarentena); i) recebimento de presentes; j) uso de recursos públicos e servidores em atividades particulares; $\mathrm{k}$ ) apropriação de fundos ou de bem móvel públicos, dentre outros.

Verifica-se que os pontos tratados nos códigos coadunam-se com os propósitos almejados no Código Internacional de Conduta para os titulares de cargos públicos. Além dos códigos de Ética, foi aprovada, em 10 de novembro de 1993, a Lei no 8.730 , a qual estabelece a obrigatoriedade da declaração de bens e rendas para o exercício de cargos, empregos e funções nos Poderes Executivo, Legislativo e Judiciário.

Outro ponto importante, objeto Código Internacional e tratado contemporaneamente no Projeto do Novo Código Penal, é a tipificação do tráfico de influência, ainda que já exista tal tipificação no atual Código Penal Brasileiro, com a alteração promovida no antigo crime de "Exploração de prestígio", por intermédio da Lei no 9.127/95. 
No condizente à Declaração das Nações Unidas contra a Corrupção e o Suborno nas transações comerciais internacionais, aprovada pela Resolução no 51/191, da Assembleia Geral, de 16 de dezembro de 1996, importante ressaltar a presença, no ordenamento jurídico brasileiro, da Convenção sobre o Combate da Corrupção de Funcionários Públicos Estrangeiros em Transações Comerciais Internacionais, do Conselho da Organização para a Cooperação Econômica e o Desenvolvimento (OCDE), ratificada pelo Brasil e promulgada pelo decreto $n$ 웅.678, de 30 de novembro de 2000.

Esta Convenção do OCDE, aprovada em Paris, em 17 de dezembro de 1997, fortemente influenciada pela Declaração da ONU incidiu diretamente sobre a Lei no 10.467, de 11 de junho de 2002, a qual acrescentou o Capítulo II-A (Dos crimes praticados por particular contra a administração pública estrangeira) ao Título XI do Código Penal Brasileiro, e inseriu dispositivo à Lei no 9.613, de 3 de março de 1998, que dispõe sobre os crimes de "lavagem" ou ocultação de bens, direitos e valores, além de criar o Conselho de Controle de Atividades Financeiras (COAF).

A Lei Anticorrupção, ainda que fortemente influenciada pela Convenção das Nações Unidas contra a Corrupção, como será visto adiante, não deixou de prever a possibilidade de competência da ControladoriaGeral da União, atualmente Ministério da Transparência, Fiscalização e Controle, de apuração, processamento e julgamento dos atos ilícitos previstos na referida Lei, quando praticados contra a administração pública estrangeira.

Como dito, a Convenção das Nações Unidas contra a Corrupção, adotada em 31 de outubro de 2003, promulgada no Brasil em 31 de janeiro de 2006, por intermédio do Decreto $n$ 우 5.687 , influenciou diretamente a Lei $\mathrm{n}^{\mathrm{o}} \mathbf{1 2 . 8 4 6}$, de $1^{\mathrm{o}}$ de agosto de 2013, popularmente conhecida como "Lei Anticorrupção", que dispõe sobre a responsabilização administrativa e civil de pessoas jurídicas pela prática de atos contra a administração pública, nacional ou estrangeira, indo ao encontro a um dos propósitos previstos da Convenção da ONU, no sentido de impor responsabilidade à pessoa jurídica, independente das pessoas físicas.

Há de se destacar, ainda, a Lei no 8.429, de 2 de junho de 1992, conhecida como lei de improbidade administrativa, que dispõe sobre 
as sanções aplicáveis aos agentes públicos nos casos de enriquecimento ilícito no exercício de mandato, cargo, emprego ou função na administração pública direta, indireta ou fundacional. Esta lei, além de coadunar-se à Convenção das Nações Unidas, caminha no propósito estabelecido também na Convenção Interamericana contra a Corrupção, aprovada pela OEA em 29 de março de 1996, sendo ratificada e promulgada no Brasil, por meio do Decreto no 4.410, em 7 de outubro de 2002, no que tange à repressão aos casos de enriquecimento ilícito.

Outro dispositivo normativo que trouxe significativo avanço à prevenção dos atos de desonestidade, coadunando-se tanto à convenção global quanto à regional, é a Lei no 12.527, de 18 de novembro de 2011, denominada Lei de Acesso à Informação, que além de impor a transparência ao poder público, possibilita o acesso às informações públicas ao cidadão.

Por fim, há de se mencionar o polêmico projeto de lei de iniciativa popular, no 4.850/2016, capitaneado pelo Ministério Público Federal, que objetiva estabelecer medidas preventivas e de combate à corrupção e demais atos lesivos ao patrimônio público e, expressamente, em sua exposição de motivos, faz menção expressão à influência sofrida tanto pela Convenção das Nações Unidas contra a Corrupção, quanto pela Convenção sobre o Combate da Corrupção de Funcionários Públicos Estrangeiros em Transações Comerciais Internacionais, do OCDE.

Enfim, como se verifica, nos últimos anos, tem havido, no Brasil, um significativo avanço normativo no que tange à prevenção e repressão aos atos de desonestidade, coadunando-se o ordenamento jurídico interno aos dispositivos internacionais e regionais que tratam do tema, corroborando a ideia da existência de uma dimensão objetiva do direito fundamental ao bom governo, da qual decorre o dever de proteção estatal.

Agora, por ser o Estado Brasileiro uma federação, necessário realizarse um estudo acerca das competências federativas para a implementação das políticas públicas acima descritas, buscando-se a efetivação do direito fundamental ao bom governo. 


\section{UMA ANÁLISE DAS COMPETÊNCIAS FEDERATIVAS À CONSECUÇÃO DAS POLÍTICAS PÚBLICAS INDISPENSÁVEIS À EFETIVAÇÃO DO DIREITO AO BOM GOVERNO}

Estabelecido o discurso de fundamentação sobre o direito ao bom governo e que dele decorre um dever, por parte dos agentes públicos em geral, de probidade, sem desvios corruptivos, com ações transparentes pautadas ao bem comum, que se concretiza através de políticas públicas de accountability, objetivando-se o controle e a responsabilização àqueles que malversarem o patrimônio público, em consonância com o esforço internacional, resta fazer uma análise acerca das competências federativas para esta atuação.

Ainda que se possa defender um estudo aprofundado acerca da possibilidade de se estabelecer um ramo autônomo do Direito voltado às especificidades da matéria, a exemplo do Direito Corruptivo, proposto por Bitencourt e Reck (2015), é preciso ter-se presente que o tema envolvendo o dever de probidade e a prevenção e repressão das condutas corruptivas engloba diferentes ramos do Direito, o que faz com que as competências para o estabelecimento das políticas públicas consectárias sejam distintas, dependendo da matéria a tratar, conforme se verá a seguir.

No tocante à competência legislativa, se a matéria a ser tratada envolver Direito Penal, não há dúvidas de que a competência é privativa da União, nos termos do Art 22, inciso I, da Constituição Federal de 1988, a exemplo da reforma do Código Penal, conforme já exposto no decorrer do trabalho.

Quanto à responsabilidade civil, em decorrência do mesmo dispositivo, depreende-se que é competência da União legislar sobre a matéria, uma vez que encontra-se abrangida pelo Direito Civil. Neste sentido, a exemplo da lei anticorrupção, que dispõe sobre a responsabilização administrativa e civil de pessoas jurídicas pela prática de atos contra a administração pública, nacional ou estrangeira, verifica-se que Estados e Municípios apenas poderão suplementar a legislação da União, no que couber.

Agora, se a competência for para legislar sobre Direito Administrativo, a competência é residual ${ }^{14}$, podendo, cada Ente federativo, estabelecer 
sua normatização, uma vez que não se encontra no texto constitucional previsão de competência exclusiva, privativa ou concorrente para a matéria.

Assim, a instituição de códigos de ética e de conduta, bem como a responsabilização administrativa nos casos de malversação do patrimônio público, ficam a cargo dos respectivos entes federados. É necessário destacar, porém, que da dimensão objetiva do direito fundamental ao bom governo decorre o dever de proteção estatal, como já mencionado acima, para que este promova ações objetivando a sua consecução, dentre elas a de legislar, razão pela qual essa competência deve ser exercida.

Diga-se, com isso, que, apesar de estarem os códigos de ética e de conduta adstritos à competência legislativa de cada ente da federação, estes possuem o dever de legislar, sob pena de negligenciarem o seu dever de proteção em relação ao bom governo.

No caso da competência para reprimir atos de improbidade administrativa, por sua vez, o debate é mais intenso, pois a matéria não é nem penal e nem civil, sendo essencialmente de Direito Administrativo.

Neste ponto, porém, a Constituição Federal de 1988, em seu art. $37, \S 4$, estabelece que "os atos de improbidade administrativa importarão a suspensão dos direitos políticos, a perda da função pública, a indisponibilidade dos bens e o ressarcimento ao erário, na forma e gradação previstas em lei, sem prejuízo da ação penal cabível”.

Parece claro, portanto, que a competência para legislar sobre improbidade administrativa é residual, podendo cada ente federativo estabelecer sua própria lei de improbidade. Significa dizer que as sanções a serem aplicadas em decorrência do ato ímprobo já estão preestabelecidas no texto constitucional, porém a definição destes atos, bem como a forma e gradação das sanções, ficam a cargo de cada um dos entes.

A título de gradação, pode-se exemplificar a suspensão dos direitos políticos, ou seja, a norma constitucional não estabelece um prazo mínimo nem máximo, o que leva a crer que cada Ente poderia estabelecer, em sua lei de improbidade administrativa, o prazo que julgasse mais adequado, podendo, inclusive estar em dissonância da Lei no 8.429/92, que parece tratar-se muito mais de uma lei federal do que de uma lei nacional ${ }^{15}$.

Ademais, quanto às hipóteses de multa e de proibição de contratar com o Poder Público ou receber benefícios ou incentivos fiscais ou 
creditícios, não elencadas no $\S 4^{\circ} \underline{0}$ do art. 37 do texto constitucional vigente, entende-se, igualmente, que poderia, cada ente da federação, em lei de sua competência, estabelecer sua existência ou não e, ainda, sua gradação, não estando adstrita àquelas previstas na conhecida Lei de Improbidade Administrativa.

Não há dúvidas de que é competência comum a todos os entes federados a conservação do patrimônio público, conforme decorre do art. 23, inciso I, da Constituição Federal de 1988, compreendido em sua máxima amplitude, o que impõe um dever de boa gestão, o qual decorre do próprio direito ao bom governo.

Em decorrência, não poderia o Ente federado deixar de exercer sua competência legislativa para definir e sancionar os atos de improbidade administrativa, eis que imposta pelo § 4ํㅡㄹ do Art 37, da Constituição, como já mencionado. Representa, no campo retórico, que, ao defender o exercício desta competência pelos demais entes, se estaria possibilitando uma maior abertura para a impunidade ou ineficácia do comando constitucional.

Não se está a sindicar, porém, a inaplicação da norma. 0 que se quer dizer é que, no sistema de competência legislativa adotado pela Constituição brasileira, não há dispositivo permissivo para que a União suprima dos demais entes (ao menos sem uma emenda ao seu texto), a competência para dispor sobre esta matéria.

Ademais, não há de se desconsiderar que da dimensão objetiva do direito fundamental ao bom governo decorre o dever estatal de protegêlo. Neste intuito, há a margem de apreciação do legislador ${ }^{16}$, que deverá estabelecê-la dentre os padrões de proporcionalidade, a fim de situar a medida adotada entre a proibição de excesso (Übermassverbot) e a proibição de proteção insuficiente (Untermassverbot) ${ }^{17}$.

Isso porque, por força do art. $37, \S 4$ o , já mencionado, ao mesmo tempo em que se exige uma proteção eficiente, o texto deixa diversas possibilidades em aberto quanto ao modo de concretização dessa proteção, principalmente quanto à definição de um ato de improbidade, bem como quanto à forma e gradação das sanções pré-estabelecidas, de modo que não se pode retirar do legislador estadual, distrital e municipal a solução adequada, desde que proporcionalmente localizada entre o excesso e a insuficiência. 
No exercício da proporcionalidade, faz-se necessário analisar se a proteção é eficaz e apropriada. Significa dizer que é necessário "verificar se a protecção satisfaz as exigências mínimas na sua eficiência e se bens jurídicos e interesses contrapostos não estão sobre-avaliados". Com efeito, "a eficácia da protecção integra, em princípio, o próprio conteúdo do dever de protecção, já que um dever de tomar medidas ineficazes não teria sentido" (CANARIS, 2009, p. 123-124).

Assim, em aplicação ao direito ao bom governo, pode-se traduzir a proibição de excesso como a vedação do legislador residual de, ao estabelecer a definição dos atos ímprobos, a forma e a gradação das sanções, acometer de forma desproporcional outros direitos fundamentais ou até, ele próprio, violar direitos fundamentais de terceiros com uma proteção (intervenção ou restrição) excessiva.

Por outro lado, a proibição de proteção insuficiente se impõe no momento em que o Estado atua insuficientemente, ficando aquém dos níveis mínimos exigidos pelos preceitos constitucionais à concretização desse direito, razão pela qual uma ação em que se estabelecesse uma sanção irrisória retiraria a eficácia da proteção constitucional.

Desse modo, verifica-se que, no campo da responsabilização penal e civil da malversação do patrimônio público, não há controvérsia quanto à competência para o estabelecimento de políticas objetivando sua prevenção e repressão. 0 mesmo não se pode dizer quanto a responsabilização por atos de improbidade administrativa, que levanta, inegavelmente, controvérsia quanto à competência legislativa, a qual poderia ser de plano pacificada com emenda à Constituição, inserindo, no rol de competências legislativas privativas da União, de forma expressa, esta matéria.

\section{CONCLUSÃO}

Como visto, no contexto do Estado Democrático de Direito não se pode negar a existência do direito fundamental ao bom governo, decorrente de uma interpretação aberta, à norma constante no art. 14, e em consonância ao princípio republicano previsto no § único do art. 1ํㅡ, ambos da Constituição Federal de 1988. 
Verifica-se, a nosso ver, que é possível se extrair do ordenamento jurídico brasileiro, conforme posto atualmente, a fundamentalidade do direito ao bom governo, que, caso seja inserido como princípio à administração pública, como se almeja em futura reforma administrativa do Estado, embora possa não se encontrar, topograficamente, no rol de direitos e garantias fundamentais, garantirá ao cidadão a possibilidade de efetivação não apenas por uma dimensão subjetiva (possibilidade de exigibilidade), mas principalmente pela sua dimensão objetiva (passará a ser norma-mandamento de atuação).

É desta dimensão objetiva, que decorre o dever de proteção à concretização do direito fundamental, que engloba o dever de legislar. A normatização objetivando-se a prevenção e repressão aos atos de malversação do patrimônio público constitui-se uma das ações que integram as políticas públicas que devem ser implementadas, a fim de que esse direito tenha a sua máxima efetividade.

0 esforço em estabelecer medidas para este fim não é exclusivo de um Estado isolado, mas espelha um esforço internacional representado pelo estabelecimento do um arcabouço normativo convencional, do qual, em grande medida, o Estado Brasileiro é parte. Observa-se que este esforço induz e reflete em medidas a serem adotadas no âmbito interno pelos Estados partes, a exemplo de algumas das analisadas no decorrer da segunda seção do trabalho.

O estabelecimento destas medidas compete ao Estado como um todo, sem desconsiderar, no âmbito interno, porém, o sistema de repartição de competências, principalmente na seara legislativa, o que faz com que haja matérias de competência privativas, concorrentes e outras residuais.

Neste campo, dentre os resultados encontrados à resolução do problema de pesquisa, verificou-se que, quanto ao estabelecimento de normas objetivando a responsabilização civil e penal, a competência é privativa da União, conforme estabelecido no inciso I, do Art. 22, da Constituição Republicana.

Quanto à competência para o estabelecimento de normas sobre Direito Administrativo, incluindo-se aqui eventuais sanções na esfera administrativo-disciplinar, não se pode negar a existência de 
competência para todos os entes, dentro da margem de apreciação de seus respectivos legisladores.

Paira controvérsia, entretanto, quanto à competência para legislar sobre improbidade administrativa, em decorrência de previsão contida no art. 37, § 4으, da Constituição, no tocante à definição dos atos de improbidade, bem como a forma e gradação da aplicação das sanções, constitucionalmente pré-estabelecidas neste dispositivo constitucional.

Como exposto no trabalho, não há de se desconsiderar o dever de proteção do Estado em estabelecer medidas (de proteção ao direito ao bom governo) situadas entre a proibição de excesso (Übermassverbot) e a proibição de proteção insuficiente (Untermassverbot), o que faria com que este tivesse a obrigação de legislar. Por outro lado, não se pode, por ausência de competência atribuída à União, retirar dos demais entes a possibilidade de legislar sobre a matéria, uma vez tratar-se, a nosso ver, de competência residual.

Por fim, há de se destacar que, como expectativa futura, a pesquisa inspira novas e contínuas investigações, sempre objetivando o aprofundamento do tema, principalmente com a realização de estudos comparados, aproximando experiências e contextos em que as técnicas e práticas implementadas possam colaborar para a mudança do atual cenário brasileiro, principalmente com a contribuição, através de um discurso de fundamentação, para eventual emenda à Constituição, a fim de incluir a improbidade administrativa ao rol de competências legislativas privativas da União, o que, a nosso ver, pacificaria a controvérsia.

\section{NOTAS}

1 Häberle (2002, p. 37) destaca que "Povo não é apenas um referencial quantitativo que se manifesta no dia da eleição e que, enquanto tal, confere legitimidade democrática ao processo de decisão. Povo é também um elemento pluralista para a interpretação que se faz presente de forma legitimadora no processo constitucional: como partido político, como opinião científica, como grupo de interesse, como cidadão".

2 "Art. 14. A soberania popular será exercida pelo sufrágio universal e pelo voto direto e secreto, com valor igual para todos [...]"

3 Apenas para se ter uma noção de nossa fundamentação, Gabardo (2009, p. 345), defendendo o direito à vida feliz, extrai da dimensão objetiva um dever de concretização deste direito, por parte do Estado, na medida que "torna-se inescusável que o caráter objetivo do direito à vida feliz consagra um dever de o Estado fazer, não fazer ou se sujeitar; para tanto lhe cabendo obviamente prestar condições materiais em certas ocasiões, mas também, e sobremaneira, propiciando 
adequadas prestações normativas, judiciais e administrativas de organização e procedimento". Não podemos olvidar que o direito ao bom governo desencadeia uma vida feliz.

4 Disponível em: http://ap.ohchr.org/documents/E/CHR/resolutions/E-CN_4-RES-2000-64.doc. Acesso em: 27 set. 2020.

5 A Organização das Nações Unidas, desde a Resolução no 415 (V), da Assembleia Geral, aprovada em $1^{\text {o }}$ de dezembro de 1950, comprometeu-se a atuar na prevenção da prática criminosa corruptiva. Disponível em: http://www.un.org/es/comun/docs/?symbol=A/RES/415(V). Acesso em: 27 set. 2020.

6 Disponível em: http://www.un.org/es/comun/docs/?symbol=A/RES/51/59. Acesso em: 27 set. 2020.

7 Disponível em: http://www.un.org/es/comun/docs/?symbol=A/RES/51/191. Acesso em: 27 set. 2020.

8 Disponível em: http://www.un.org/es/comun/docs/?symbol=A/RES/54/128. Acesso em: 27 set. 2020.

9 Disponível respectivamente em: <http://www.un.org/es/comun/docs/?symbol=A/ RES/67/192>; <http://www.un.org/es/comun/docs/?symbol=A/RES/68/195> e <http:// www.un.org/es/comun/docs/?symbol=A/RES/69/199>. Acesso em: 27 set. 2020.

10 A Convenção foi ratificada pelo Brasil e promulgada pelo Decreto no 5.687/2006. Disponível em: https://www.planalto.gov.br/ccivil_03/_Ato2004-2006/2006/Decreto/D5687.htm. Acesso em: 27 set. 2020.

11 A Convenção foi ratificada pelo Brasil e promulgada pelo Decreto nำ4.410/2002. Disponível em: http://www.planalto.gov.br/ccivil_03/decreto/2002/D4410.htm. Acesso em: 27 set. 2020.

12 Importante referir que, além da Declaração da ONU, há também a Convenção sobre o Combate da Corrupção de Funcionários Públicos Estrangeiros em Transações Comerciais Internacionais, concluída em 17 de dezembro de 1997 e adotada pelo Conselho da Organização para a Cooperação Econômica e o Desenvolvimento (OCDE), a qual, inclusive, foi ratificada pelo Brasil e promulgada em 30 de novembro de 2000, através do Decreto no 3.678. Esta convenção não será objeto de estudo no presente trabalho.

13 A teoria do "dever de proteção" (Schutzpficht) foi desenvolvida pelo Tribunal Constitucional Alemão partindo-se da concepção da dimensão objetiva dos direitos fundamentais, notadamente nas decisões envolvendo o aborto. Seu cerne sustenta-se na decorrência de um dever oriundo das normas de direitos fundamentais que impõe ao Estado a proteção aos particulares contra agressões aos seus bens jurídicos constitucionalmente previstos, mesmo que estas decorram das relações geradas entre si. Significa dizer que ao mesmo tempo em que os direitos fundamentais determinam ao Estado uma conduta negativa (no sentido de não violá-los), implicam um comportamento positivo, obrigando-o a intervir, seja de forma preventiva ou repressiva, também nas relações privadas (LEAL; ALVES, 2018)

14 Nas palavras de Kerbauy (2001, p. 53), a competência legislativa residual faz parte da história constitucional brasileira. Compreende-se que, quando o texto Constitucional não elenca competência específica para determinado ente, poderão os demais Entes da escala de verticalidade legislar. Exemplo: Se não há competência específica para a União, poderão os Estados, o Distrito Federal e o Município legislar sobre dada matéria.

15 Compreenda-se lei Federal como aquela que, embora aprovada pelo Congresso Nacional, aplica-se ao âmbito restrito do Ente Federal (União), enquanto a Lei Nacional compreenderia norma geral para todos os Entes da Federação, dentro da competência legislativa para tanto outorgada pela Constituição, a exemplo das matérias previstas no art. 22 da Constituição Federal (SILVA, 1964, p. 57-60).

16 A margem de apreciação do legislador, com origem a partir da jurisprudência e da doutrina administrativista francesa e germânica, constitui na liberdade (discricionária) de criação e conformação legislativa conforme a Constituição e o Direito (ROJAS, 2013, p. 48). Ou seja, dentro dos limites estabelecidos pelo Direito, há uma margem discricionária para que o legislador, dentro de um juízo de conveniência e oportunidade, que atenda critérios de proporcionalidade, edite o ato normativo que entenda mais adequado à situação.

17 A respeito do tema, ver Leal e Alves (2018). 


\section{REFERÊNCIAS}

BITENCOURT, Caroline Müller; RECK, Janriê Rodrigues. Construção pragmáticosistêmica dos conceitos básicos do Direito Corruptivo: observações sobre a possibilidade do tratamento da corrupção como um ramo autônomo do Direito. In: A\&C - R. de Dir. Administrativo \& Constitucional. Belo Horizonte, ano 15, $\mathrm{n}$. 62, p. 123-140, out./dez. 2015.

BRASIL. Constituição da República Federativa do Brasil de 1988. Disponível em: http://www.planalto.gov.br/ccivil_03/constituicao/ConstituicaoCompilado. htm. Acesso em: 27 set. 2020.

BRASIL. Código de Conduta da Alta Administração Federal, de 21 de agosto de 2000. Disponível em: https://www.planalto.gov.br/ccivil_03/Codigos/ codi_conduta/Cod_conduta.htm. Acesso em: 27 set. 2020.

BRASIL. Código Penal Brasileiro. Disponível em: http://www.planalto.gov.br/ ccivil_03/decreto-lei/Del2848.htm. Acesso em: 27 set. 2020.

BRASIL. Decreto $n^{-}$1.171, de 22 de junho de 1994. Aprova o Código de Ética Profissional do Servidor Público Civil do Poder Executivo Federal. Disponível em: https://www.planalto.gov.br/ccivil_03/decreto/d1171.htm>. Acesso em 27 set. 2020.

BRASIL. Decreto no 5.687, de 31 de janeiro 2006. Promulga a Convenção das Nações Unidas contra a Corrupção, adotada pela Assembléia-Geral das Nações Unidas em 31 de outubro de 2003 e assinada pelo Brasil em 9 de dezembro de 2003. Disponível em: https://www.planalto.gov.br/ccivil_03/_Ato20042006/2006/Decreto/D5687.htm. Acesso em: 27 set. 2020.

BRASIL. Decreto $n^{0} 4.410$, de 7 de outubro de 2002. Promulga a Convenção Interamericana contra a Corrupção, de 29 de março de 1996, com reserva para o art. XI, parágrafo 1o, inciso "c". Disponível em: http://www.planalto.gov.br/ ccivil_03/decreto/2002/D4410.htm. Acesso em: 27 set. 2020.

BRASIL. Lei $n^{\circ}$ 8.730, de 10 de novembro de 1993. Estabelece a obrigatoriedade da declaração de bens e rendas para o exercício de cargos, empregos e funções nos Poderes Executivo, Legislativo e Judiciário. Disponível em: https://www. planalto.gov.br/ccivil_03/leis/l8730.htm. Acesso em: 27 set. 2020. 
BRASIL. Lei no 8.429, de 2 de junho de 1992. Dispõe sobre as sanções aplicáveis aos agentes públicos nos casos de enriquecimento ilícito no exercício de mandato, cargo, emprego ou função na administração pública direta, indireta ou fundacional e dá outras providências. Disponível em: https://www.planalto. gov.br/ccivil_03/Leis/L8429.htm. Acesso em: 27 set. 2020.

BRASIL. Lei $n^{\circ}$ 12.846, de 1ํo de agosto de 2013. Dispõe sobre a responsabilização administrativa e civil de pessoas jurídicas pela prática de atos contra a administração pública, nacional ou estrangeira, e dá outras providências. Disponível em: http://www.planalto.gov.br/ccivil_03/_ato2011-2014/2013/ lei/l12846.htm> Acesso em: 27 set. 2020.

BRASIL. Lei no 12. 527, de 18 de novembro de 2011. Dispõe sobre a lei de acesso á informação. Disponível em: http://www.planalto.gov.br/ccivil_03/_ato20112014/2011/lei/l12527.htm>. Acesso em 27 set. 2020.

BRASIL. Projeto de Lei $n^{\circ}$ 4.850/2016. Dispõe sobre as dez medidas contra a corrupção. Disponível em: http://www.camara.gov.br/proposicoesWeb/ficha detramitacao?idProposicao=2080604. Acesso em: 27 set. 2020 .

BRASIL. Projeto de Lei no 236/2012. Dispõe sobre o Novo Código Penal Brasileiro. Disponível em: http://www25.senado.leg.br/web/atividade/materias/-/ materia/106404. Acesso em: 27 set. 2020.

CANARIS, Claus-Wilhelm. Direitos Fundamentais e Direito Privado. Trad. Ingo Wolfgang Sarlet e Paulo Mota Pinto. 2. reimp. Lisboa: Almedina, 2009.

CANOTILHO, José Joaquim Gomes. Direito Constitucional e Teoria da Constituição. 4. ed. Lisboa: Almedina, 2000.

CASTRO, Alberto. Buen gobierno, derechos humanos y tendencias innovadoras en el derecho público. In: (Ed). Buen gobierno y derechos humanos. Nuevas perspectivas en el derecho público para fortalecer la legitimidad democrática de la administración pública en el Perú. Lima: PUCP, 2014.

CLÉVE, Clèmerson Merlin. A eficácia dos direitos fundamentais sociais. In: Revista de Direito Constitucional e Internacional. vol. 54. São Paulo: Revista dos Tribunais, 2006. 
GABARDO, Emerson. O JARDIM E A PRAÇA PARA ALÉM DO BEM E DO MAL: uma antítese ao critério de subsidiariedade como determinante dos fins do Estado social. Programa de Pós-Graduação em Direito (Tese). Curitiba: UFPR, 2009.

HÄBERLE, Peter. Hermenêutica Constitucional - A Sociedade Aberta dos intérpretes da Constituição: contribuição para a interpretação pluralista e "procedimental" da Constituição. Trad. Gilmar Ferreira Mendes. 1. reimp.

Porto Alegre: Sergio Antonio Fabris, 2002.

HÄBERLE. El Estado Constitucional. Trad. Héctor Fix-Fierro. 1. reimp. Ciudad de México: Universidade Nacional Autônoma, 2003.

HESSE, Konrad. A força normativa da Constituição. Trad. Gilmar Ferreira Mendes. Porto Alegre: Sergio Antonio Fabris, 1991.

LEAL, Mônia Clarissa Hennig; ALVES, Felipe Dalenogare. O ESTADO BRASILEIRO E O DEVER DE PROTEÇÃO AO TRABALHADOR: o controle de

convencionalidade aplicado pelo Tribunal Superior do Trabalho brasileiro como instrumento de concretização dos direitos fundamentais no case Ivanildo Bandeira vs. Amsted Maxion. In: MAIA, Luciano Mariz; LIRA, Yulgan (Orgs). Controle de Convencionalidade: Temas Aprofundados. Salvador: Juspodivm, 2018.

LEAL, Rogério Gesta. PATOLOGIAS CORRUPTIVAS NAS RELAÇÕES ENTRE ESTADO, ADMINISTRAÇÃO PÚBLICA E SOCIEDADE: causas, consequências e tratamentos. Santa Cruz do Sul: EdUNISC, 2013.

LUHMANN, Niklas. A constituição como aquisição evolutiva. Tradução de Menelick de Carvalho Netto. In: Il futuro della costituzione. Torino: Einaudi, 1996.

KERBAUY, Maria Teresa Miceli. FEDERALISMO, DESCENTRALIZAÇÃo E DEMOCRACIA. In: Revista Estudos de Sociologia. v. 6. n. 10., 2001.

MÜLLER, Friedrich. Métodos de Trabalho do Direito Constitucional. Trad. Peter Naumann. 2. ed. São Paulo: Max Limonad, 2000. 
ONU. Resolução no 2000/64 do Conselho de Direitos Humanos. Aprovada em 26 de abril de 2000. Disponível em: http://ap.ohchrorg/documents/E/CHR/ resolutions/E-CN_4-RES-2000-64.doc. Acesso em: 14 jul. 17.

ONU. Resolução no 415 (V), da Assembleia Geral, aprovada em 1ํo de dezembro de 1950. Disponível em: http://www.un.org/es/comun/docs/?symbol=A/ RES/415(V). Acesso em: 27 set. 2020.

ONU. Resolução no 51/59, da Assembleia Geral, aprovada em 12 de dezembro de 1996. Disponível em: http://www.un.org/es/comun/docs/?symbol=A/ RES/51/59. Acesso em: 27 set. 2020.

ONU. Resolução no 51/191, da Assembleia Geral, aprovada em 16 de dezembro de 1996. Disponível em: http://www.un.org/es/comun/docs/?symbol=A/ RES/51/191. Acesso em: 27 set. 2020.

ONU. Resolução 54/128, da Assembleia Geral, aprovada em 17 de dezembro de 1999. Disponível em: http://www.un.org/es/comun/docs/?symbol=A/ RES/54/128. Acesso em: 27 set. 2020.

ONU. Resolução 68/195, da Assembleia Geral, aprovada em 18 de dezembro de 2013. Disponível em: http://www.un.org/es/comun/docs/?symbol=A/ RES/68/195. Acesso em: 27 set. 2020.

ONU. Resolução 69/199, da Assembleia Geral, aprovada em 18 de dezembro de 2014. Disponível em: http://www.un.org/es/comun/docs/?symbol=A/ RES/69/199. Acesso em: 27 set. 2020.

ONU. Resolução 67/192, da Assembleia Geral, aprovada em 20 de dezembro de 2012. Disponível em: http://www.un.org/es/comun/docs/?symbol=A/ RES/67/192. Acesso em: 27 set. 2020.

PÉREZ LUÑO, Antonio Enrique. Los Derechos Fundamentales. 11. ed. Madrid: Tecnos, 2013.

RAMINA, Larissa O. Ação internacional contra a corrupção. 3. reimp. Curitiba: Juruá, 2008. 
RAMINA, Larissa. Tratamento Jurídico Internacional da Corrupção: a Convenção Interamericana contra a Corrupção da OEA e a Convenção sobre o combate da corrupção de funcuionários públicos estrangeiros em transações comerciais internacionais da OCDE. In: Revista da Faculdade de Direito da Universidade Federal do Paraná. v. 39. Curitiva: UFPR, 2003.

RODRIGUEZ-ARANA, Jaime Muñoz. Sobre el derecho fundamental a la

buena administración y la posición jurídica del ciudadano. A\&C R. de Dir. Administrativo \& Constitucional. Belo Horizonte, ano 12, n. 47, p. 13-50, jan./ mar. 2012.

ROJAS, Marcela Peredo. El margen de apreciación del legislador y el control del error manifiesto. Algunas consideraciones a partir de la jurisprudência del Consejo Constitucional Francês y del Tribunal Constitucional Alemán. In: Estudios Constitucionales. v. 11. n. 2, p. 47 - 96, 2013.

SARLET, Ingo Wolfgang. A eficácia dos Direitos Fundamentais. 8. ed. Porto Alegre: Livraria do Advogado, 2007.

SILVA, José Afonso da. Princípios do Processo de Formação das Leis no Direito Constitucional. São Paulo: Revista dos Tribunais, 1964.

Recebido em: 29-08-2018

Aprovado em: 08-10-2020 


\section{Felipe Dalenogare Alves}

Doutor (com bolsa Capes/Prosup - Tipo II). Mestre em Direito pela Universidade de Santa Cruz do Sul (UNISC). Especialista em Direito Público pela Universidade Cândido Mendes, Direito Administrativo pela Faculdade Dom Alberto, Gestão Pública Municipal pela Universidade Federal de Santa Maria, Educação em Direitos Humanos pela Universidade Federal do Rio Grande e Direito Militar pela Faculdade Futura. MBA Executivo em Coaching pela Faculdade Futura. Professor permanente de Direito Administrativo e Prática Administrativa no Centro de Ensino Integrado Santa Cruz - CEISC. Coordenador do curso de Pós-Graduação em Direito Militar e da Pós-Graduação em Direito Constitucional e Administrativo, ambos da Universidade de Santa Cruz do Sul - UNISC. Professor convidado em cursos de Pós-Graduação em diferentes instituições. Autor de Obras Jurídicas em editoras nacionais e internacionais. Pesquisador e Palestrante em Direito Público com ênfase em Direito Administrativo e Constitucional. E-mail: felipe@ estudosdedireito.com.br

\section{Mônia Clarissa Hennig Leal}

Pós-doutorado pela Universität Heidelberg (Ruprecht-Karls) (2007). Doutorado em Direito pela Universidade do Vale do Rio dos Sinos (2005). Doutorado sanduíche pela Universitat Heidelberg (Ruprecht-Karls) (2004). Mestrado em Direito pela Universidade de Santa Cruz do Sul (2001). Graduação em Direito pela Universidade de Santa Cruz do Sul (1999). Professora concursada da Universidade de Santa Cruz do Sul, onde ministra as disciplinas de Controle Jurisdicional de Políticas Públicas (Doutorado em Direito), de Jurisdição Constitucional (Mestrado em Direito), de Ações Constitucionais e de Metodologia da Pesquisa (Pós-Graduação Lato Sensu) e de Teoria e de Direito Constitucional (Graduação em Direito). Coordenadora do Programa de Pós-Graduação em Direito - Mestrado e Doutorado da Universidade de Santa Cruz do Sul - UNISC, onde também atuou na criação do Centro Integrado de Estudos e Pesquisas em Políticas Públicas - CIEPPP e do Observatório da Jurisdição Constitucional Latino-americana, que contam com recursos do FINEP. Membro do Conselho Superior e do Comitê Assessor da Área de Ciências Humanas e Sociais da FAPERGS. Professora Visitante junto à Ernst-Moritz-Arndt Universität Greifswald, Alemanha. Pesquisadora Visitante junto à Ruprecht-Karls Universität Heidelberg, Alemanha e junto à Paris-Lodron Universität Salzburg, Áustria. E-mail: moniah@unisc.br

Universidade de Santa Cruz do Sul, Programa de Pós-Graduação em Direito Mestrado e Doutorado.

Avenida Independência, 2293

Santa Cruz do Sul, RS - 96800000 
